\title{
(3) \\ LC-MS/MS assay for Acetazolamide, A Carbonic Anhydrase Inhibitor in Human Plasma and its Clinical Application
}

\author{
Anjaneyulu Narapusetti ${ }^{12^{*}}$, Syama Sundar Bethanabhatla ${ }^{3}$, Anbazhagan \\ Sockalingam ${ }^{4}$ and Nageswara Rao Pilli ${ }^{5}$ \\ ${ }^{1}$ Department of Pharmaceutical Analysis, School of Pharmaceutical Sciences and Technologies, Jawaharlal \\ Nehru Technological University Kakinada, Kakinada-533 003, India. \\ ${ }^{2}$ Department of Pharmaceutical Analysis, Geethanjali College of pharmacy, Cheeryal-501 301, India. \\ ${ }^{3}$ Department of Chemistry, Yogi Vemana University, Kadapa-516 003, India.
}

${ }^{4}$ Department of Pharmaceutical Chemistry, Surya School of Pharmacy, NH-45, GST Road, Vikravandi, Villpuram-605 652, India.

${ }^{5}$ Department of Bioanalysis, PCR Laboratories, Ramanthapur, Hyderabad-500 013, India.

\section{ABSTRACT}

Objective: The objective of this research was to develop a novel liquid chromatography/tandem mass spectrometry (LC-MS/MS) method for the determination of acetazolamide in human plasma. Methods: An analytical method based on LC-MS/MS (API-4000) has been developed and validated for the quantitative determination of acetazolamide in human plasma using acetazolamide d3 as Internal Standard (IS). After Solid phase extraction (SPE), analyte and the IS were chromatographed on a C18 columns using a isocratic mobile phase composed of $0.1 \%$ formic acid buffer and acetonitrile $(30: 70, \mathrm{v} / \mathrm{v})$ pumped at a flow rate of $0.80 \mathrm{~mL} / \mathrm{min}$. Results: Precision and accuracy of the method was determined using five analytical batches in the concentration range of $50.3-12046 \mathrm{ng} / \mathrm{mL}$. All the validation experiments were carried out as per the US FDA guidelines and results met the acceptance criteria. Conclusion: The proposed LC-MS/MS assay method is simple, rapid and sensitive for the determination of acetazolamide in human plasma. A chromatographic run time of 2.0 min, allow us to analyze more than 300 samples in a day.

Key words: Acetazolamide, Human plasma, LC-MS/MS, Method validation, Pharmacokinetics.

\begin{tabular}{|l|l|}
\hline \multicolumn{2}{|c|}{ Access this article online } \\
\hline \multirow{2}{*}{ Journal Sponsor } & \multicolumn{1}{|l|}{ Website: } \\
www.jyoungpharm.org \\
\hline \multirow{2}{*}{ www.phcognet } & \\
\cline { 2 - 3 } & DOI: \\
& $10.5530 /$ jyp.2015.4s.5 \\
\hline
\end{tabular}

\section{INTRODUCTION}

Acetazolamide is a carbonic anhydrase inhibitor commonly used to treat glaucoma. The drug is also used for the treatment of epilepsy, mountain sickness, periodic paralysis, central sleep apnea and idiopathic intracranial hypertension. ${ }^{1,2}$ Acetazolamide decreases the aqueous

*Address for correspondence:

Mr. Anjaneyulu Narapusetti, Research Scholar, Department of Pharmaceutical Analysis, School of Pharmaceutical Sciences and Technologies, Jawaharlal Nehru Technological University, Kakinada-533 003, India. E-mail: narapusetti@gmail.com 


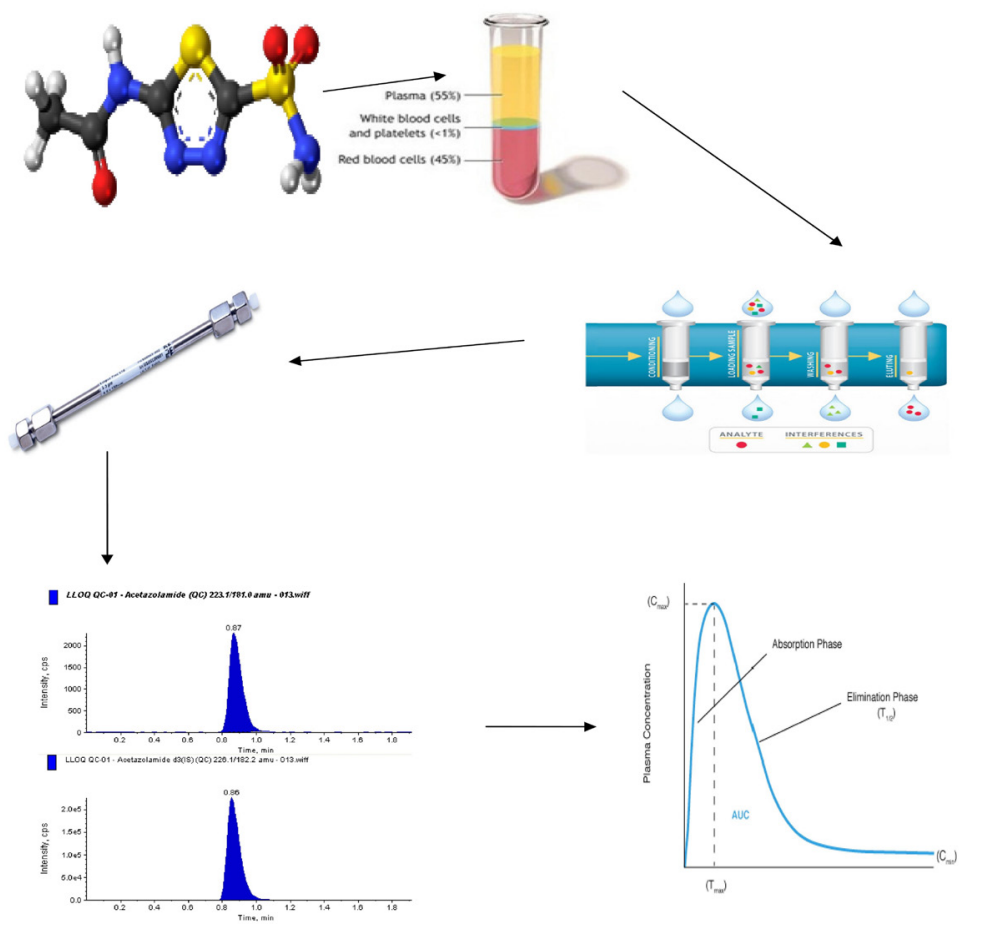

Graphical Abstract

humor formation, there by reduces the Intraocular pressure (IOP). However, the usefulness of the drug has been limited due to high incidence of side effects associated with its continued use. The etiology of many of the adverse effects is unclear, may be due to acidosis or carbon dioxide retention. ${ }^{3}$ After oral administration, the peak blood levels were attained in $4-8 \mathrm{~h}$ with elimination half-life $\left(t_{1 / 2}\right)$ about $10-15$ h. ${ }^{1,2}$

Based on the literature, many HPLC based analytical methods have been reported for the determination of acetazolamide in human plasma, ${ }^{4-6}$ rat plasma and tissues, ${ }^{7}$ human urine ${ }^{8}$ and in dosage forms. ${ }^{9}$ The conventional HPLC methods must sacrifice time, resolution or sensitivity. Hence there is a necessity to develop fast or ultra-fast methods such as LC-MS/MS without any loss of separation efficiency and sensitivity. Recently, $\mathrm{Li}$ et al..$^{10}$ reported an LC-MS/MS method for the determination of acetazolamide in beagle dog plasma using Protein precipitation (PP) technique for the sample preparation. Till date, none of the method describes the development process, various validation experiments, stability studies and suitability for application to pharmacokinetic/ bioequivalence studies.

This paper presents, for the first time, the complete development and validation of a simple, sensitive and selective LC-MS/MS method in multiple reaction monitoring (MRM) mode for the quantification of acetazolamide in human plasma using acetazolamide $\mathrm{d} 3$ as an Internal standard (IS) to avoid the possible matrix effect related problems and variability in recovery between analyte and the IS. This sensitive method requires only $100 \mu \mathrm{L}$ human plasma for Solid-phase extraction (SPE) technique, minimum usage of organic solvents and demonstrates excellent performance in terms of ruggedness with a sample cut off time $2.0 \mathrm{~min}$.

\section{MATERIALS AND METHODS}

\section{Standards and chemicals}

The reference sample of acetazolamide (99.46\%) and acetazolamide d3 (99.20\%) were obtained from Clearsynth Labs Limited (Mumbai, India). HPLC grade acetonitrile and methanol were purchased from J. T. Baker (Phillipsburg, NJ, USA), while analytical grade formic acid was from Merck Ltd (Mumbai, India). The blank $\mathrm{K}_{2}$ human plasma sample was procured from Deccan's Pathological Lab's (Hyderabad, India). Ultra pure water was prepared by using Milli Q water purification system procured from Millipore (Bangalore, India).

\section{LC-MS/MS instrument and conditions}

An HPLC system (Shimadzu, Kyoto, Japan) equipped with a Hypurity advance column $(50 \times 4.6 \mathrm{~mm}, 5 \mu \mathrm{m})$, a binary LC-20AD prominence pump, an auto sampler 
(SIL-HTc) and a solvent degasser (DGU-20A $)$ was used for the study. Aliquot of $10 \mu \mathrm{L}$ of the processed samples were injected into the column, which was maintained at 35 $\pm 2^{\circ} \mathrm{C}$ temperature. An isocratic mobile phase composed of a mixture of $0.1 \%$ formic acid buffer and acetonitrile $(30: 70, \mathrm{v} / \mathrm{v})$ was used to separate the analyte and the IS from the endogenous components. The mobile phase was pumped at a flow rate of $0.80 \mathrm{~mL} / \mathrm{min}$ into the mass spectrometer electrospray ionization chamber. API-4000 triple quadrupole mass spectrometer (AB Sciex, Foster City, CA, USA) equipped with a Turboionspray ${ }^{\mathrm{TM}}$ in positive ion mode was used for the quantification of analyte. The ion spray voltage was set at $5000 \mathrm{~V}$ with interface temperature $500^{\circ} \mathrm{C}$. The source parameters viz. the nebulizer gas (GS1), auxiliary gas (GS2), curtain gas and collision gas were set at $35,40,20$, and 8 psi, respectively. The various potentials namely Declustering potential (DP), Collision energy (CE), Entrance potential (EP) and Collision cell exit potential (CXP) were set at 40, 22, 10, $10 \mathrm{~V}$ for acetazolamide and 42, $21,10,10 \mathrm{~V}$ for the IS. Detection of the ions was carried out in the Multiple-reaction monitoring mode (MRM), by monitoring the transition pairs of $m / ₹ 223.1$ precursor ion to the $m / z 181.0$ for acetazolamide and $m / z^{226.1}$ precursor ion to the $m / z 182.2$ product ion for the IS. Quadrupoles (Q1 and Q3) were set on unit resolution. Dwell time was set at $200 \mathrm{~ms}$. The data acquisition was performed by Analyst software $^{\mathrm{TM}}$ (version 1.4.2).

\section{Preparation of Spiked plasma samples}

Stock solutions of acetazolamide and the IS were prepared in HPLC grade methanol $(1 \mathrm{mg} / \mathrm{mL})$. Working solutions were prepared using a mixture of methanol and water (50:50, v/v; diluent). Calibration samples were prepared at a concentration levels of 50.3, 101, 300, 601, 1202, 2403, 4806, 7227, 9637 and $12046 \mathrm{ng} / \mathrm{mL}$ in K2 EDTA human plasma. Similarly, Quality control (QC) samples were also prepared at concentrations of 50.8 (lower limit of quantitation quality control, LLOQ QC), 152 (low quality control, LQC), 1263 (medium quality control, MQC1), 6016 (MQC2) and $10026 \mathrm{ng} / \mathrm{mL}$ (high quality control, HQC).

\section{Extraction procedure}

A $100 \mu \mathrm{L}$ aliquot of human plasma sample was spiked with the IS dilution $(20 \mu \mathrm{L}$ of $50.0 \mu \mathrm{g} / \mathrm{mL}$ of acetazolamide d3). To this, $100 \mu \mathrm{L}$ of formic acid buffer (5\%) was added after vortex mixing for $10 \mathrm{~s}$. The sample mixture was loaded onto a Orochem Celerity Deluxe SPE cartridge $(30 \mathrm{mg} / 1$ $\mathrm{mL}$ ) that was pre-conditioned with $1.0 \mathrm{~mL}$ of methanol followed by $1.0 \mathrm{~mL}$ water. The cartridge was washed with
$1.0 \mathrm{~mL}$ of water followed by $1.0 \mathrm{~mL}$ of $10 \%$ methanol. Analyte and the IS were eluted with $1.0 \mathrm{~mL}$ of methanol. Eluent was evaporated under gentle stream of nitrogen at $40^{\circ} \mathrm{C}$ and reconstituted with $500 \mu \mathrm{L}$ of mobile phase. Aliquot of $10 \mu \mathrm{L}$ of the sample was injected into the chromatographic system.

\section{Method validation parameters}

A thorough and complete method validation of acetazolamide in human plasma was carried out as per US FDA ${ }^{11}$ guidelines. The parameters determined were carryover test, selectivity, matrix effect, sensitivity, linearity, precision and accuracy, recovery, dilution integrity, long run evaluation and stability.

\section{Pharmacokinetic study design}

A pharmacokinetic study was performed in healthy Indian male subjects $(n=7)$ under fed condition. All the volunteers provided with written informed consent. Blood samples were collected after oral administration of $500 \mathrm{mg}$ acetazolamide ER capsule at $0.5,1,1.5,2,2.5$, $3,4,4.5,5,5.5,6,7,8,9,10,12,16,24,36$ and $48 \mathrm{~h}$ and collected in $\mathrm{K}_{2}$ EDTA vacutainer $(5 \mathrm{~mL})$ collection tubes (BD, Franklin, NJ, USA). A predose sample was also collected before administration of each drug formulation. The tubes were centrifuged at $3200 \mathrm{rpm}$ for $10 \mathrm{~min}$ and the plasma was collected. The collected plasma samples were stored at $-70 \pm 10^{\circ} \mathrm{C}$. Plasma samples were spiked with the IS and processed as per the proposed extraction procedure. WinNonlin (Version 5.2) software package was use to calculate the pharmacokinetic parameters by non-compartmental model. An incurred sample reanalysis (ISR) was also performed as per FDA recommendations by selecting the 2 samples from each subject (14 samples in total) near $C_{\max }$ and the elimination phase in the pharmacokinetic profile of the drug. The percent difference between the ISR value and the initial value should not be more than $\pm 20 \%{ }^{12}$

\section{RESULTS}

\section{Method development}

The aim of the present work is to develop a simple, sensitive and rapid LC-MS/MS method for the quantification of acetazolamide in human plasma suitable for pharmacokinetic and bioequivalence studies. Initially, analyte and the IS were tuned in positive and negative ionization modes using ESI source. The high intense signals were obtained in positive ion mode than the negative mode. 

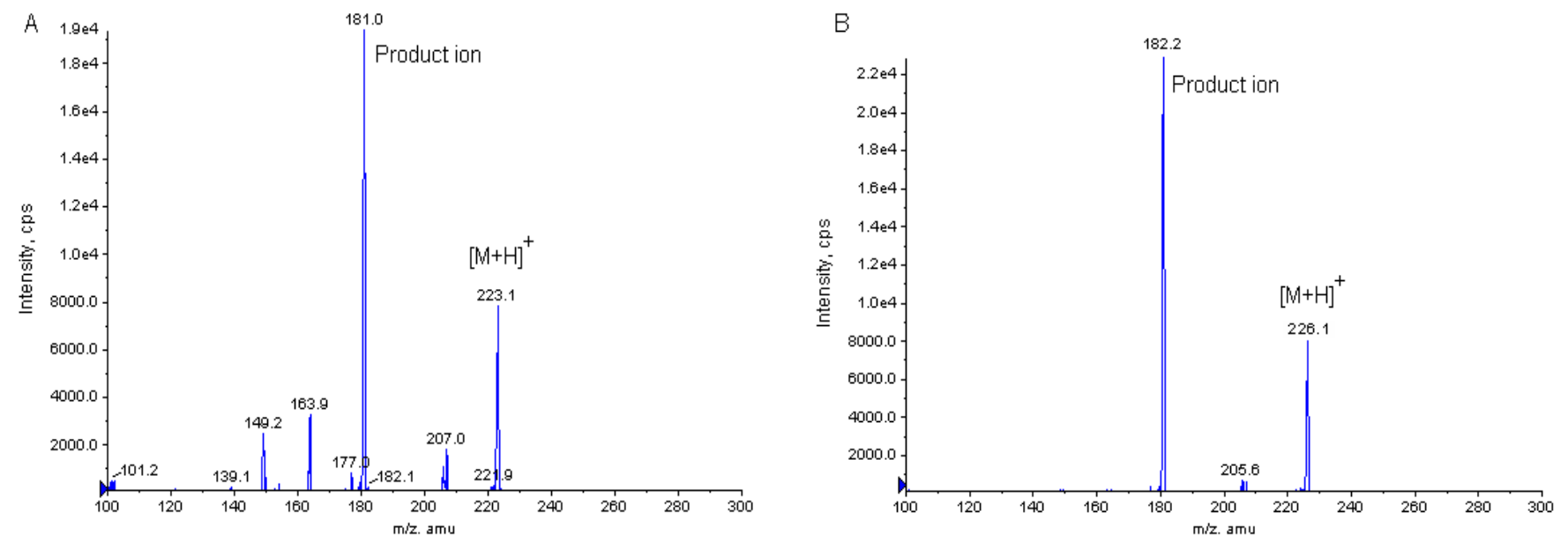

Figure 1: Product ion mass spectra of $[\mathrm{M}+\mathrm{H}]^{+}$of $(\mathrm{A})$ Acetazolamide and (B) Acetazolamide-d3 (IS)

Data in the Multiple reaction monitoring (MRM) mode was considered, which showed better selectivity. The compound and source dependent parameters were suitably altered to get most intense signals and reproducible response. Data in the Multiple reaction monitoring (MRM) mode was considered, which showed better selectivity. ${ }^{13}$ The positive ion spray mass spectrum revealed a protonated molecular by monitoring the transition pairs of $\mathrm{m} / \mathrm{z} 223.1$ precursor ion to the $\mathrm{m} / \mathrm{z} 181.0$ product ion for acetazolamide (Figure 1a) and $m / z^{226.1}$ precursor ion to the $\mathrm{m} / \mathrm{z} 182.2$ product ion for the IS (Figure 1b).

Once the mass spectrometer conditions were set, the mobile phase composition was optimized with acetonitrile and methanol by varying its proportion with volatile buffers like ammonium formate, ammonium acetate, as well as acid additives like formic acid and acetic acid in varying strength. Finally an isocratic mobile phase composed of $0.1 \%$ formic acid buffer and acetonitrile $(30: 70, \mathrm{v} / \mathrm{v})$ at a flow rate of $0.8 \mathrm{~mL} / \mathrm{min}$ gave symmetric peak shape, best sensitivity and better separation for analyte and the IS. Among the various chromatographic columns tested for their suitability Hypurity advance $(50 \times 4.6,5 \mu \mathrm{m})$ column gave good peak shape and response even at lowest concentration level for the analyte. The retention time of analyte and the IS $(0.90$ and $0.90 \mathrm{~min}$, respectively) were low enough allowing a short run time of $2.0 \mathrm{~min}$.

For LC-MS analysis, there should be a proper extraction procedure which can yields good recovery with no or minimal matrix effect. Hence, Solid phase extraction (SPE) was tested. SPE was tried with Oasis HLB, Starata $\mathrm{X}$ polymeric sorbent, Orochem celerity deluxe, Bond Elut Plexa and Orpheus $\mathrm{C}_{18}$ extraction cartridges with/without acidic buffer addition. Of all the above, promising results were obtained with Orochem celerity deluxe SPE cartridge
(30 mg/1 mL), which can produce a clean chromatogram for a blank sample and yields the highest recovery for the analyte and the IS from the plasma. Stable labeled isotopes as internal standard increases the bioanalytical assay precision and accuracy. Hence, in the present work acetazolamide stable labeled isotope acetazolamide $\mathrm{d} 3$ was employed as an internal standard.

\section{Carryover test, selectivity and chromatography}

No significant carryover was observed in blank sample after injection highest concentration of analyte (ULOQ; upper limit of quantitation). The degree of interference by endogenous plasma components with the analyte and the internal standard was assessed by inspection of chromatograms derived from processed blank plasma sample. As displayed in Figure 2a no significant interference in the blank plasma traces was observed from endogenous components in drug-free plasma at the retention time of analyte and the IS. Moreover, no significant interference was found from the IS to the MRM channel of the analyte (Figure 2b). Figure 2c shows a representative MRM chromatogram resulted from the analysis of LLOQ sample (50.3 ng/mL). A representative chromatograms resulting from the analysis of subject blank plasma sample and $7 \mathrm{~h}$ subject plasma sample after the administration of a $500 \mathrm{mg}$ oral single dose of acetazolamide is shown in the Figure 3.

\section{Sensitivity}

The Signal-to-noise ratio $(\mathrm{S} / \mathrm{N})$ was measured at a concentration of $50.3 \mathrm{ng} / \mathrm{mL}$, which is set as a lowest limit of reliable quantification (LLOQ) for the analyte. The $\mathrm{S} / \mathrm{N}$ ratio at this concentration was found to be $\geq 10$. The precision and accuracy at LLOQ concentration were found to be $1.56 \%$ and $97.6 \%$, respectively. 


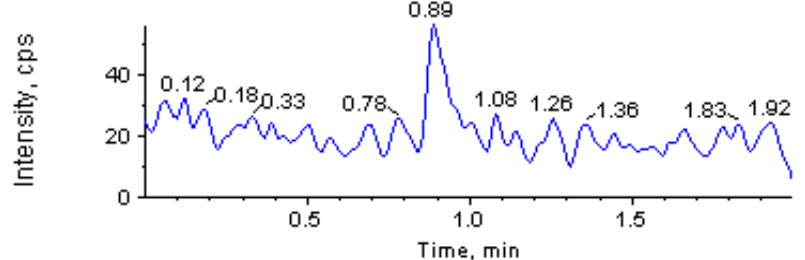

Blank+lS - Acetazolamide (Blank) 223.1/181.0 amu

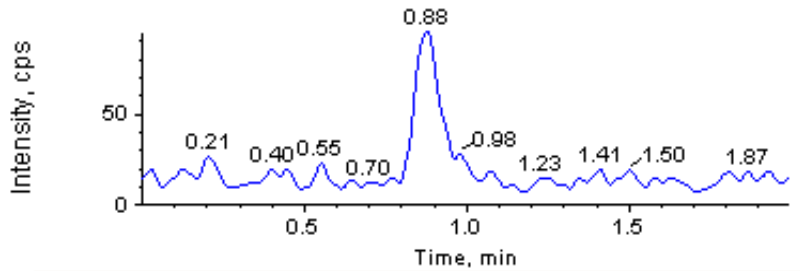

STD-A - Acetazolamide (Standard) 223.1/181.0 amu

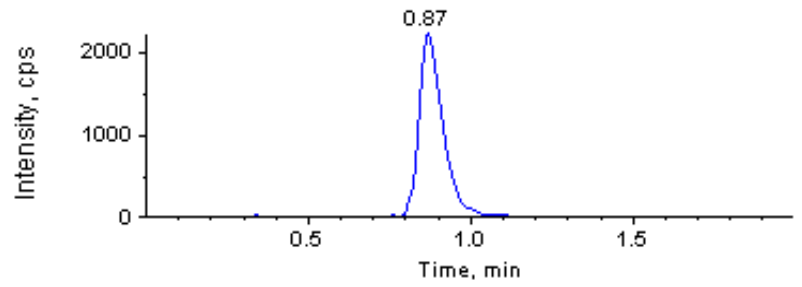

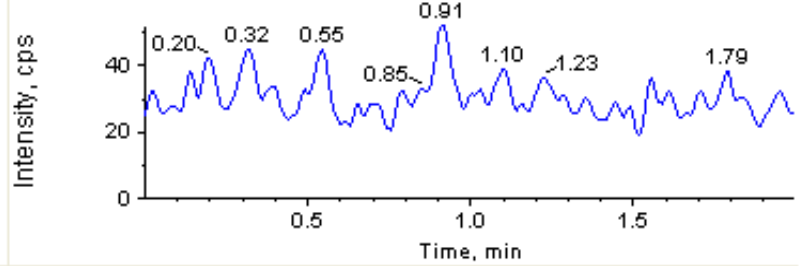

Blank+IS - Acetazolamide d3(IS) (Blank) 226.1/182.2 amu

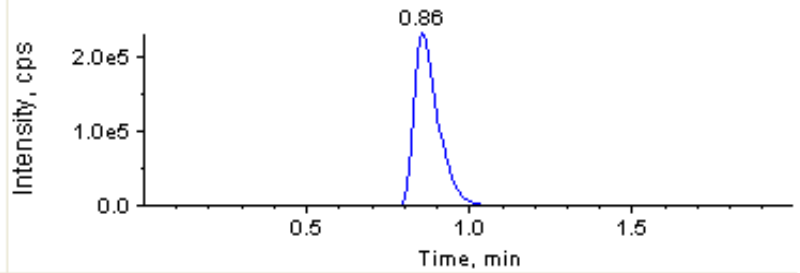

STD-A - Acetazolamide d3(IS) (Standard) 226.1/182.2 amu

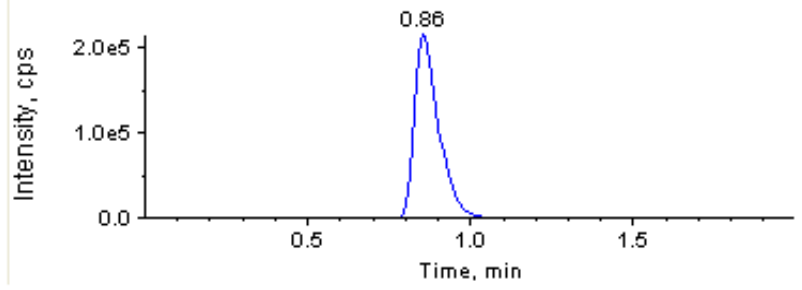

Figure 2: Typical MRM chromatograms of Acetazolamide (left panel) and IS (right panel) in human blank plasma (A), and human plasma spiked with IS (B), a LLOQ sample along with IS (C)

A S1P1-Predose - Acetazolamide (Unknown) 223.1/181.0 amı

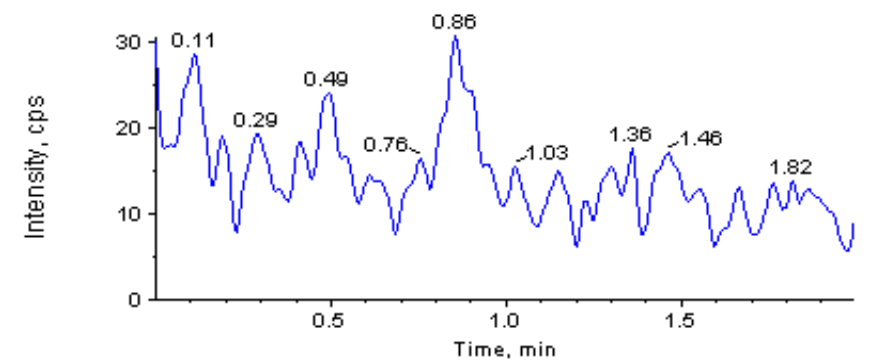

B

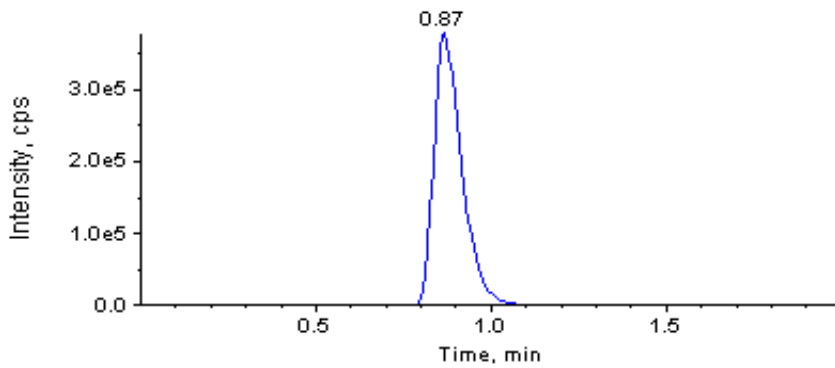

S1P1-Predose - Acetazolamide d3(IS) (Unknown) 226.1/182.2 amu

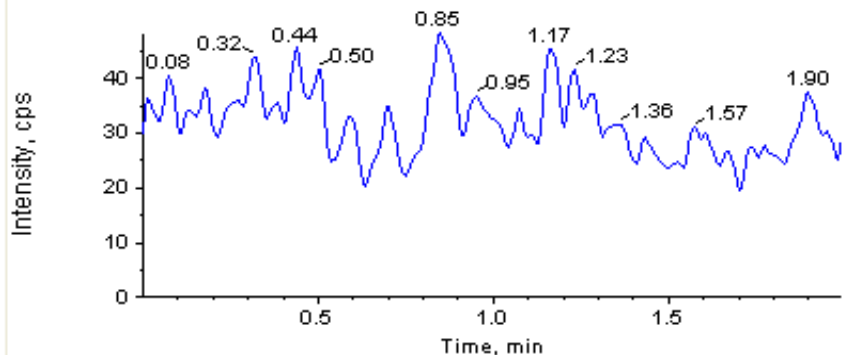

S1P1-7.00 hrs - Acetazolamide d3(IS) (Unknown) 226.1/182.2 amu

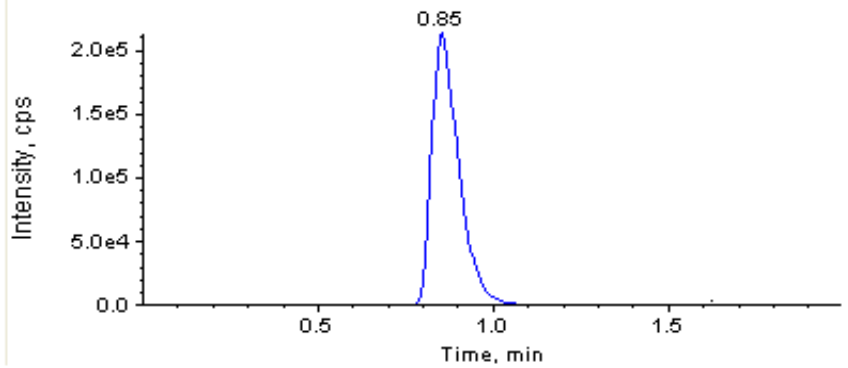

Figure 3: MRM chromatograms resulting from the analysis of subject blank plasma sample (A) and $7 \mathrm{~h}$ subject plasma sample (B), after the administration of a $500 \mathrm{mg}$ oral single dose of acetazolamide ER capsule. The sample concentration was determined to be $9666 \mathrm{ng} / \mathrm{mL}$ 


\begin{tabular}{|c|c|c|c|c|}
\hline Quality control & Run & $\begin{array}{l}\text { Concentration found } \\
\text { Mean } \pm \text { SD }(\mathrm{ng} / \mathrm{mL})\end{array}$ & Precision (\%) & Accuracy (\%) \\
\hline \multicolumn{5}{|c|}{ Intra-day variations ( $\mathrm{n}=12$ at each concentration) } \\
\hline LLOQ & & $50.5 \pm 4.56$ & 9.04 & 99.4 \\
\hline LQC & & $148 \pm 15.3$ & 10.3 & 97.6 \\
\hline MQC1 & & $1242 \pm 11.2$ & 0.91 & 98.3 \\
\hline MQC2 & & $5668 \pm 85.8$ & 1.51 & 94.2 \\
\hline HQC & & $9735 \pm 145$ & 1.49 & 97.1 \\
\hline \multicolumn{5}{|c|}{ Inter-day variations ( $n=30$ at each concentration) } \\
\hline LLOQ & & $51.3 \pm 3.27$ & 6.37 & 101 \\
\hline LQC & & $150 \pm 12.7$ & 8.43 & 99.0 \\
\hline MQC1 & & $1251 \pm 25.9$ & 2.07 & 99.0 \\
\hline MQC2 & & $5873 \pm 201$ & 3.42 & 97.6 \\
\hline HQC & & $9925 \pm 265$ & 2.67 & 99.0 \\
\hline
\end{tabular}

Nominal concentrations of LLOQ, LQC, MQC1, MQC2 and HQC are 50.8, 152, 1263, 6016 and 10026 ng/mL, respectively.

\begin{tabular}{|c|c|c|c|c|}
\hline Stability test & $\begin{array}{c}\text { QC (spiked } \\
\text { concentration, } \mathrm{ng} / \mathrm{mL} \text { ) }\end{array}$ & Mean \pm SD $(n g / m L)$ & $\begin{array}{l}\text { Precision } \\
\text { (\%) }\end{array}$ & $\begin{array}{l}\text { Accuracy/ } \\
\text { Stability (\%) }\end{array}$ \\
\hline $\begin{array}{l}\text { Aautosampler stability } \\
\left.\text { (at } 10^{\circ} \mathrm{C} \text { for } 65 \mathrm{~h}\right)\end{array}$ & $\begin{array}{c}152 \\
10026\end{array}$ & $\begin{array}{c}136 \pm 1.85 \\
9220 \pm 92.5\end{array}$ & $\begin{array}{l}1.36 \\
1.00\end{array}$ & $\begin{array}{l}89.7 \\
92.0\end{array}$ \\
\hline $\begin{array}{l}\text { Wet extract stability } \\
\left(\text { at } 2-8^{\circ} \mathrm{C} \text { for } 61 \mathrm{~h}\right)\end{array}$ & $\begin{array}{c}152 \\
10026\end{array}$ & $\begin{array}{l}136 \pm 0.87 \\
9167 \pm 106\end{array}$ & $\begin{array}{l}0.64 \\
1.15\end{array}$ & $\begin{array}{l}89.8 \\
91.4\end{array}$ \\
\hline $\begin{array}{l}\text { Bench top stability } \\
\text { (12 } \mathrm{h} \text { at room } \\
\text { temperature) }\end{array}$ & $\begin{array}{c}152 \\
10026\end{array}$ & $\begin{array}{l}141 \pm 1.72 \\
9403 \pm 125\end{array}$ & $\begin{array}{l}1.22 \\
1.33\end{array}$ & $\begin{array}{l}92.7 \\
93.8\end{array}$ \\
\hline $\begin{array}{c}\text { Freeze-thaw stability } \\
\text { (4 cycles) }\end{array}$ & $\begin{array}{c}152 \\
10026\end{array}$ & $\begin{array}{c}136 \pm 2.74 \\
9232 \pm 94.3\end{array}$ & $\begin{array}{l}2.02 \\
1.02\end{array}$ & $\begin{array}{l}89.8 \\
92.1\end{array}$ \\
\hline $\begin{array}{c}\text { Reinjection stability } \\
(25 \mathrm{~h})\end{array}$ & $\begin{array}{c}152 \\
10026\end{array}$ & $\begin{array}{c}144 \pm 2.92 \\
10316 \pm 103\end{array}$ & $\begin{array}{l}2.03 \\
1.00\end{array}$ & $\begin{array}{l}94.7 \\
103\end{array}$ \\
\hline $\begin{array}{l}\text { Long-term Stability } \\
\text { (at-70 }{ }^{\circ} \mathrm{C} \text { for } 101 \text { days) }\end{array}$ & $\begin{array}{c}152 \\
10026\end{array}$ & $\begin{array}{c}158 \pm 1.86 \\
10258 \pm 201\end{array}$ & $\begin{array}{l}1.18 \\
1.96\end{array}$ & $\begin{array}{l}104 \\
102\end{array}$ \\
\hline $\begin{array}{l}\text { Short-term Stability } \\
\text { (at }-20^{\circ} \mathrm{C} \text { for } 15 \text { days) }\end{array}$ & 15210026 & $\begin{array}{c}139 \pm 3.52 \\
9283 \pm 56.3\end{array}$ & $\begin{array}{l}2.54 \\
0.61\end{array}$ & $\begin{array}{l}91.5 \\
92.6\end{array}$ \\
\hline
\end{tabular}

\section{Linearity and precision and accuracy}

Linearity of the proposed method was established over the concentration range of $50.3-12046 \mathrm{ng} / \mathrm{mL}$ using five calibration curves. The mean linear equation obtained for acetazolamide was $y=(0.000180 \pm 0.000022) x+$ $(0.000357 \pm 0.000398)$, where $y$ is the peak area ratio of the analyte/IS and $x$ the concentration of the analyte. The mean correlation coefficient values were in the range of 0.9984-0.9992 during entire course of validation.

Intra-day and Inter-day precision and accuracy results of acetazolamide for five analytical runs in spiked quality control samples are summarized in Table 1.

\section{Recovery and dilution integrity}

With the proposed SPE method, the mean overall recovery obtained for acetazolamide was $79.4 \pm 3.04 \%$ with the precision $(\% \mathrm{CV})$ range of $1.29 \%-6.69 \%$ and the recovery of the IS was $77.1 \%$ (measured at a concentration of $50.00 \mu \mathrm{g} / \mathrm{mL}$ ).

The upper concentration limit of acetazolamide can be extended to $20052 \mathrm{ng} / \mathrm{mL}$ by using half (1:2) or quarter (1:4) dilution with screened human blank plasma. The precision $(\% \mathrm{CV})$ for dilution integrity of half and quarter dilution was found to be $1.40 \%$ and $1.02 \%$ and the accuracy results were found to be $97.2 \%$ and $95.0 \%$, respectively.

\section{Long run evaluation}

A total of 196 samples were analyzed in a single run. 40 sets of each of LQC, MQC1, MQC2 and HQC samples (stored at $-70^{\circ} \mathrm{C}$ ) and 6 sets each of freshly spiked quality control samples were processed and analyzed along with freshly spiked calibration curve standards. 160 QC's out of 160 QC's of long run evaluation and 24 QC's out of 24 QC's of freshly spiked were within $15 \%$ of their respective nominal values. 


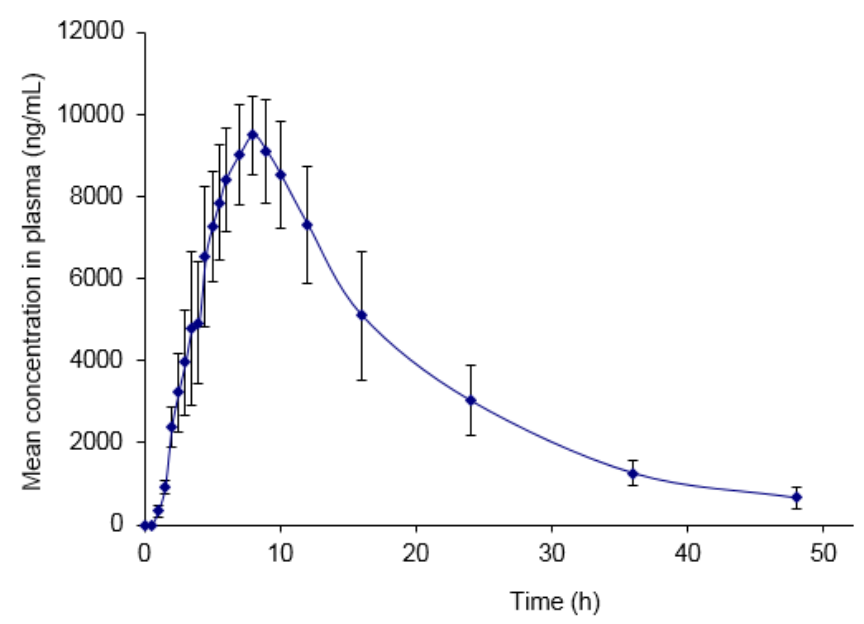

Figure 4: Mean plasma concentration-time profile of Acetazolamide in human plasma following oral dosing of acetazolamide $(500 \mathrm{mg}$ ER capsule) to healthy volunteers $(n=7)$

\section{Stability studies}

The mean $\%$ nominal values were found to be within $\pm 15 \%$ of the predicted concentrations for the analyte at their LQC and HQC levels and the precision (\%CV) values were within 15\% (Table 2) for all the stability tests carried out during the entire course of method validation. All the above stability results were found to be within the acceptable limits during the entire validation.

\section{Clinical application and incurred samples reanalysis}

The proposed method was successfully used to estimate the real time plasma samples obtained from the pharmacokinetic study $(n=7)$. The mean concentration $\left(C_{\max }\right)$ in plasma $(10090 \pm 687 \mathrm{ng} / \mathrm{mL})$ for acetazolamide was attained at $7.71 \pm 1.38 \mathrm{~h}\left(t_{\max }\right)$ with a half-life $\left(t_{1 / 2}\right)$ of $11.2 \pm 3.53 \mathrm{~h}$. The area under the plasma concentrationtime curve from time zero to last measurable time point $\left(\mathrm{AUC}_{0-\uparrow}\right)$ and area under the plasma concentration time curve from time zero to infinity time point $\left(\mathrm{AUC}_{0 \text {-inf }}\right)$ for acetazolamide were $169562 \pm 23937$ and $181260 \pm 24439$ $\mathrm{ng} * \mathrm{~h} / \mathrm{mL}$, respectively. Figure 4 depicts the mean plasma concentration $v$ s time profile of acetazolamide in healthy subjects. The obtained study data is validated through ISR. The concentration difference between the initial and the ISR values for all the tested samples are presented in the Table 3 and the results indicating good reproducibility of the proposed method.

\section{CONCLUSION}

The LC-MS/MS assay presented in this paper is simple, rapid and sensitive for the determination of acetazolamide

\begin{tabular}{cccc}
$\begin{array}{c}\text { Table 3: Incurred samples re-analysis data of Acetazolamide } \\
\text { Sample }\end{array}$ & $\begin{array}{c}\text { Initial conc. } \\
\text { (ng/mL) }\end{array}$ & $\begin{array}{c}\text { Re-assay } \\
\text { conc. }(\mathbf{n g} / \mathbf{m L})\end{array}$ & $\begin{array}{c}\text { Difference } \\
\text { a }\end{array}$ \\
\hline $\mathbf{1}$ & 9666 & 9126 & 5.75 \\
$\mathbf{2}$ & 530 & 498 & 6.27 \\
$\mathbf{3}$ & 8959 & 9416 & -4.97 \\
$\mathbf{4}$ & 585 & 611 & -4.34 \\
$\mathbf{5}$ & 9665 & 10235 & -5.73 \\
$\mathbf{6}$ & 1248 & 1199 & 3.99 \\
$\mathbf{7}$ & 9749 & 10197 & -4.49 \\
$\mathbf{8}$ & 775 & 839 & -7.87 \\
$\mathbf{9}$ & 10828 & 9676 & 11.2 \\
\hline $\mathbf{1 0}$ & 405 & 385 & 4.97 \\
$\mathbf{1 1}$ & 9442 & 8930 & 5.57 \\
\hline $\mathbf{1 2}$ & 564 & 520 & 8.20 \\
$\mathbf{1 3}$ & 10016 & 9814 & 2.04 \\
\hline $\mathbf{1 4}$ & 520 & 602 & -14.5 \\
\hline
\end{tabular}

aExpressed as [(initial conc.-re-assay conc.)/average] $\times 100 \%$.

in human plasma. To the best of knowledge, this is the first LC-MS/MS report describes the complete method development and validation process for the determination of acetazolamide in human plasma suitable for pharmacokinetic or bioavailability/bioequivalence application. With the reported LLOQ $(50.3 \mathrm{ng} / \mathrm{mL})$ we could quantify acetazolamide up to $48 \mathrm{~h}$ post-dosing in human volunteers. The simple solid phase extraction method gave high and reproducible recoveries for the analyte and the IS from plasma. A sample turnover rate of less than 2.0 min makes it an attractive procedure in high-throughput bioanalysis of acetazolamide.

\section{ACKNOWLEDGEMENTS}

The authors gratefully acknowledge PCR Laboratories (Hyderabad, India) for providing necessary facilities to carry out this work.

\section{CONFLICT OF INTEREST}

The authors declare no conflict of interest.

\section{ABBREVIATION}

$\begin{array}{ll}\text { LC-MS/MS: } & \begin{array}{l}\text { Liquid Chromatography/ } \\ \text { Tandem Mass Spectrometry } \\ \text { Multiple Reaction-Monitoring }\end{array} \\ & \text { Mode } \\ \text { US FDA: } & \text { United States Food and Drug } \\ & \text { Administration } \\ \text { IOP: } & \text { Intraocular Pressure } \\ \text { HPLC: } & \text { High Performance Liquid }\end{array}$




$\begin{array}{ll} & \text { Chromatography } \\ \text { PP: } & \text { Protein Precipitation } \\ \text { IS: } & \text { Internal Standard } \\ \text { SPE: } & \text { Solid-Phase Extraction } \\ \text { DP: } & \text { Declustering Potential } \\ \text { CE: } & \text { Collision Energy } \\ \text { EP: } & \text { Entrance Potential } \\ \text { CXP: } & \text { Collision Cell Exit Potential } \\ \text { LLOQ QC: } \quad \text { Lower Limit of Quantitation }\end{array}$

$\begin{array}{ll} & \text { Quality Control } \\ \text { LQC: } & \text { Low Quality Control } \\ \text { MQC: } & \text { Medium Quality Control } \\ \text { HQC: } & \text { High Quality Control } \\ \text { EDTA: } & \text { Ethylenediaminetetraacetic acid } \\ \text { ER: } & \text { Extended Release } \\ \text { ISR: } & \text { Incurred Sample Reanalysis } \\ \text { ESI: } & \text { Electro Spray Ionisation } \\ \text { ULOQ: } & \text { Upper Limit of Quantitation }\end{array}$

\section{Highlights of Paper}

- First LC-MS/MS report for the determination of acetazolamide in human plasma.

- The method employs only $100 \mu \mathrm{L}$ of plasma volume and achieved good sensitivity.

- Isotope labeled compound used as an internal standards to get better precision and accuracy.

- The total analysis time is shortest compared to all existing methods.

- Method reproducibility was demonstrated by incurred sample reanalysis.

\section{Author Profile}

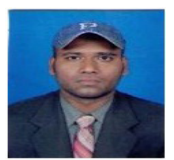

- Anjaneyulu Narapusetti: Is a Research scholar at School of Pharmaceutical Sciences and Technologies, Jawaharlal Nehru Technological University Kakinada, India. Also, he is an Associate Professor at Geethanjali College of pharmacy, India. He did post-graduation in Pharmacy from Dr. MGR medical University, India. His areas of interest in Pharmaceutical Analysis, Bioanalysis of drugs, New Research Drugs, HPLC-MS and HPLC.

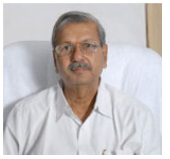

- Syama Sundar Bethanabhatla: Obtained his Ph.D from Nagarjuna University,Guntur. Currently, he is positioned as the vice- chancellor in Yogi Vemana University, Kadapa, India. His Areas of interest in Solvent extraction, Spectrophotometer, Reaction kinetics and mechanisms, Kinetic methods of analysis, Environmental Chemical analysis, Pharmacology and Pharmaceutical analysis, many Research Projects Carried out through CSIR, AICTE and UGC.

\section{REFERENCES}

1. Yano I, Takayama A, Takano M, Inatani M, Tanihara H, Ogura Y, et al. Pharmacokinetics and pharmacodynamics of acetazolamide in patients with transient intraocular pressure elevation. Eur J Clin Pharmacol. 1998; 54(1): 63-8.

2. Tripathi KD. Acetazolamide. Essentials of Medical Pharmacology, $5^{\text {th }}$ ed. New Delhi: Jaypee Publishers; 2004. p. 533.

3. Epstein DL, Grant WM. Carbonic anhydrase inhibitor side effects: serum chemical analysis. Arch Opthalmol. 1997; 95(8): 1378-82.

4. Zarghi A, Shafaati A. Rapid determination of acetazolamide in human plasma. J Pharm Biomed Anal. 2002; 28(1): 169-72.

5. Hossie RD, Mousseau N, Sved S, Brien R. Quantitation of acetazolamide in plasma by high-performance liquid chromatography. J Pharm Sci. 1980; 69(3): 348-9.

6. Hartley R, Lucock M, Becker M, Smith IJ, Forsythe WI. Solidphase extraction of acetazolamide from biological fluids and subsequent analysis by high-performance liquid chromatography. J Chromatogr. 1986; 377: 295-305.

7. Ichikawa N, Naora K, Hirano H, Iwamoto K. Quantitation of acetazolamide in rat plasma, brain tissue and cerebrospinal fluid by high-performance liquid chromatography. J Pharm Biomed Anal. 1998; 17(8): 1415-21.

8. Herráez-Hernández R, Campíns-Falcó P, Sevillano-Cabeza A. Determination of acetazolamide in human urine samples by reversed-phase high-performance liquid chromatography in the presence of xanthines. J Chromatogr. 1992; 582(1): 181-7.

9. Gomaa ZS. Determination of acetazolamide in dosage forms by high performance liquid chromatography. Biomed Chromatogr. 1993; 7(3): 134-5.

10. Li X, Li N, Wang C, Deng S, Sun X, Zhang W, et al. Development and validation of a simple and reliable LC-MS/MS method for the determination of acetazolamide, an effective carbonic anhydrase inhibitor, in plasma and its application to a pharmacokinetic study. Drug Res. (Stuttg) 2014; 64(9): 499-504.

11. US DHHS, FDA and CDER. Guidance for Industry: Bioanalytical Method Validation. US Department of Health and Human Services, Food and Drug Administration, Center for Drug Evaluation and Research and Center for Veterinary Medicine, 2001. Available at: http://www/ fda.gov/cder/guidance/index.htm.

12. De Boer T, Wieling J. Incurred sample accuracy assessment: design of experiments based on standard addition. Bioanalysis 2011; 3(9): 983-92.

13. Das R, Pal TK. Validation of liquid chromatography-tandem mass spectrometry for mevalonate in human plasma: Incompetent effects between treated atorvastatin and its combination with olmesartan in cardiovascular patients. J Young Pharm. 2014; 6(2): $50-7$. 